Artículo recebido el 9 de julio de 2020; Aceptado para publicación el 10 de agosto de 2020

\title{
Políticas curriculares para adiar o fim do mundo e poéticas sobre a existência na educação escolar indígena
}

\section{Políticas curriculares para posponer el fin del mundo y poéticas sobre la existencia em la educación escolar indígena \\ Curricular policies to postpone the end of the world and poetics about existence in indigenous school education}

\author{
Ubiratã Jorge de Souza Gomes ${ }^{1}$ \\ Júlio César Augusto do Valle ${ }^{2}$
}

\begin{abstract}
Resumo
O propósito deste texto consiste em resgatar e discutir experiências realizadas no campo das políticas curriculares da/na educação escolar indígena, inspiradas diretamente pela Etnomatemática ou com ela capazes de estabelecer substantivas conexões, em especial diante do contexto de rápida expansão do contágio do vírus Covid-19. Para isso, consideram-se as pesquisas-práticas-políticas recentemente mobilizadas por membros-pesquisadores do Grupo de Estudos e Pesquisa em Etnomatemática (GEPEm) da Faculdade de Educação da Universidade de São Paulo, que têm se dedicado ao currículo e às suas políticas em seus estudos e investigações. Valemo-nos dos graves aprendizados decorrentes da experiência ameaçadora da Pandemia em que nos encontramos para compreender o território das políticas curriculares como local privilegiado para os debates que ensejam diferentes, contraditórios e complexos, pontos de vistas, interesses e relações de poder desiguais. Nesse contexto, tratamos de possíveis e potenciais contribuições das pesquisas sobre os currículos, inspiradas pela Etnomatemática, para tensionar e desestabilizar as compreensões de currículo (e) de matemática, ao passo em que também apresentamos e discutimos político-práticas capazes de nos oferecer subsídios consistentes, necessários à resistência e à reinvenção curricular que propomos.
\end{abstract}

Palavras-chave: Educação Matemática; Educação escolar indígena; Etnomatemática; Currículo; Práticas emancipatórias.

\section{Resumen}

El propósito de este texto es rescatar y discutir experiencias llevadas a cabo en el campo de las políticas curriculares de/en la educación escolar indígena, inspiradas directamente por la etnomatemática o capaces de establecer conexiones sustantivas, especialmente en el contexto de rápida expansión de Covid- 19. Para eso, consideramos las investigaciones-prácticas-políticas recientemente movilizadas por los miembros investigadores del Grupo de Estudios e Investigación en Etnomatemática (GEPEm) de la Facultad de Educación de la Universidad de São Paulo, que se han dedicado al plan de estudios y sus políticas, en sus estudios e investigaciones. Utilizamos las serias lecciones aprendidas de la experiencia amenazadora de Pandemia en la que nos encontramos para comprender el terreno de las políticas curriculares como un lugar privilegiado para debates que ofrecen puntos de vista, intereses y relaciones de poder diferentes, contradictorias, complejas y desiguales. En este contexto, abordamos las posibles y potenciales contribuciones de la investigación sobre los planes de estudio, inspirados por la

1 Possui graduação em Formação Intercultural Superior Professor Indígena pela Universidade de São Paulo (2008). Atuou como professor na educação escolar Indígena na Escola Estadual Indígena Aldeia Bananal, professor coordenador do Núcleo Pedagógico (PCNP) da Diretoria de Ensino da Região de São Vicente (DERSV), e hoje atua como diretor da Escola Indígena Tangará. Tem experiência na área de Educação, com ênfase em Educação escolar indígena, falante fluente da língua Tupi-guarani. Integrante do Núcleo de Educação Indígena do Estado de São Paulo e do Fórum de Articulação dos Professores Indígenas do Estado de São Paulo (FAPISP).

2 Professor do Instituto de Matemática e Estatística da Universidade de São Paulo (IME-USP). Membro-pesquisador do GEPEm, desde 2012, e ex-Secretário Municipal de Educação e Cultura de Pindamonhangaba (2017-2020). 
etnomatemática, para tensar y desestabilizar los conocimientos del currículo (e) de matemáticas, al tiempo que presentamos y discutimos prácticas de políticas capaces de ofrecernos subsidios consistentes, necesarios para la resistencia y la reinvención curricular que proponemos.

Palabras clave: Educación matemática; Educación escolar indígena; Etnomatemática; Plan de estudios; Prácticas emancipatorias.

\begin{abstract}
The purpose of this text is to rescue and discuss experiences carried out in the field of curricular policies of / in indigenous school education, inspired directly by Ethnomathematics or capable of establishing substantive connections, especially in the context of the rapidly expanding context of the Covid- 19. For this, we consider the research-practices-policies recently mobilized by research members of the Group of Studies and Research in Ethnomathematics (GEPEm) of the Faculty of Education of the University of São Paulo, who have dedicated themselves to the curriculum and its policies in their studies and investigations. We make use of the serious lessons learned from the threatening experience of Pandemic in which we find ourselves to understand the territory of curricular policies as a privileged place for debates that offer different, contradictory and complex, unequal points of view, interests and power relations. In this context, we address possible and potential contributions of research on curricula, inspired by Ethnomathematics, to tension and destabilize mathematics curriculum (e) understandings, while also presenting and discussing policy-practices capable of offering us consistent subsidies. , necessary for the resistance and the curricular reinvention that we propose.
\end{abstract}

Keywords: Mathematics Education; Indigenous school education; Ethnomathematics; Curriculum; Emancipatory practices.

\title{
1. INTRODUÇÃO
}

\author{
Mas é possível voltar? \\ Digamos que seja. \\ As religiões todas acreditam nisso. \\ Mas o que temos nós a ver com religiões? \\ Nossa pergunta não é essa. \\ Não pode ser. \\ Formulemos melhor. \\ É desejável voltar? \\ Se sim, desejável para quem? \\ E voltar como? \\ "Olha para a frente menino", diz o professor. \\ Então a tarefa é voltar olhando para a frente? \\ Seria esse o sentido de re-voltar? \\ Gustavo Colombini
}

Em face do cenário atual que vivemos, diante de uma ameaça invisível que nos mantém todos reféns, isolados, impedindo-nos de conviver de forma harmoniosa com quem amamos. O vírus nos pegou de surpresa e nos faz refletir sobre qual é o verdadeiro sentido da existência humana na Terra. Vivemos uma triste realidade nas comunidades Indígenas, por conta do vírus Sars-CoV-2, causador do Covid-19, chegou de uma forma arrasadora nas comunidades indígenas ceifando a vida de anciãos e anciãs, bibliotecas vivas para os povos nativos, causando perdas irreparáveis para essas populações, como ocorreu no passado com outras epidemias. Ao equiparar com um surto de Influenza A 
Souza, U. \& Valle, J. (2020). Políticas curriculares para adiar o fim do mundo e poéticas sobre a existência na educação escolar indígena. Revista Latinoamericana de Etnomatemática, 13(1), 189-214. DOI: $10.22267 /$ relatem.20131.54

(H1N1) em uma comunidade Guarani no Rio de Janeiro, o pesquisador Andrey Moreira Cardoso, do Departamento de Endemias da Escola Nacional de Saúde Pública, da Fiocruz (Fundação Oswaldo Cruz) que se dedica à pesquisa de doenças respiratórias em populações indígenas, analisa que:

Limitações na disponibilidade de territórios tradicionais para manutenção dos modos de vida indígena, de acesso a saneamento básico, bem como infecções recorrentes, desnutrição e anemia e emergência de doenças crônicas tornam as populações indígenas um grupo ainda mais vulnerável à epidemia atual. (Cardoso, 2020).

As populações indígenas têm sofrido muito no decorrer dos séculos, com um histórico de genocídio ocasionado por massacres e epidemias que dizimaram grande parte desses povos, ao encontro do que relata a pesquisadora Maria Rita Kehl (Kehl, Gomes \& Takuá, (2016), durante a Comissão Nacional da Verdade (CNV), “o extermínio foi muito numeroso e, muito maior do que o dos moradores das cidades que lutaram contra a ditadura por causa das epidemias, foi um extermínio por omissão", em relação às populações indígenas.

Em meio a essa realidade que estamos vivendo está a educação escolar que, foi obrigada a se reinventar para manter o mínimo de vínculo com o alunado. A maior parcela da comunidade está com dificuldades em acompanhar o ensino remoto, não é diferente para população indígena. $\mathrm{O}$ direito à uma educação diferenciada, em contraponto ao modelo hegemônico imposto pelos europeus ao invadirem nosso território, nos deu uma nova perspectiva para pensar numa educação escolar realmente de qualidade, a partir da Constituição Federal de 1988, em seu art. 210 (Brasil, 1988), que garantiu a população o indígena, o direito de poder manifestar suas culturas em sala de aula. E, alguns anos mais tarde, em 1996, com a Lei de Diretrizes e Bases da Educação Nacional (LDBEN), normatizou a educação escolar indígena:

Art. 78. O Sistema de Ensino da União, com a colaboração das agências federais de fomento à cultura e de assistência aos índios, desenvolverá programas integrados de ensino e pesquisa, para oferta de educação escolar bilingüe e intercultural aos povos indígenas, com os seguintes objetivos:

I - Proporcionar aos índios, suas comunidades e povos, a recuperação de suas memórias históricas; a reafirmação de suas identidades étnicas; a valorização de suas línguas e ciências;

II - Garantir aos índios, suas comunidades e povos, o acesso às informações, conhecimentos técnicos e científicos da sociedade nacional e demais sociedades indígenas e não-índias. (Brasil, 1996)

Com o amparo de leis que nos dão autonomia para fazer a diferença em nossas comunidades educativas, acreditamos que chegou o momento de pôr em prática o que 
queremos de projeto de vida para que realmente eleve a educação escolar indígena para um patamar de "Educação diferenciada", bem como de qualidade. A esse respeito, concordamos com a seguinte colocação do educador Antonio Nóvoa:

[...] a pandemia não nos trouxe nada de novo, mas sim, revelou inúmeros problemas e que, seria uma catástrofe ainda maior se a escola não mudasse e continuasse na mesma. Enfatiza que ela, a escola, precisa "metamorforsear-se" e, o professor é a peça fundamental neste processo como agente construtor dessa nova realidade [...] (Nóvoa, 2020).

Diante desta nova realidade em que nos encontramos, está em nossas mãos, educadores, propiciar uma reflexão sobre como os princípios e pressupostos da Etnomatemática, bem como suas experiências mobilizadas em práticas-políticas-pesquisas, podem orientar ou têm orientado as concepções e as práticas da educação indígena - em especial, da escola indígena vista como diferenciada em termos político-culturais - que deve ter à frente dela educadores indígenas formados para uma prática pedagógica ancorada na interculturalidade. Assim sendo, o que pretendemos consiste em elaborar, pensarfazer, aulas que ponham os alunos e as alunas como agentes construtores do conhecimento, participativa e criticamente, tendo o professor como um interlocutor privilegiado dessa aprendizagem, onde a ensinagem pressupõe um vínculo indissociável entre o educador e o educando (Freire, 2012).

Em meados da década de 70 consolidou-se outro modo de pensar e valorizar as práticas de inspiração matemática de cada grupo étnico, de acordo com a sua especificidade. Segundo o educador matemático Ubiratan D'Ambrósio, seu idealizador, o Programa Etnomatemática:

tem seu comportamento alimentado pela aquisição de conhecimento, de fazer(es) e de saber(es) que lhes permitam sobreviver e transcender, através de maneiras, de modos, de técnicas, de artes (techné ou 'ticas') de explicar, de conhecer, de entender, de lidar com, de conviver com (mátema) a realidade natural e sociocultural (etno) na qual ele, homem, está inserido (D'Ambrosio, 2000, p. 99).

Diferentes pesquisas-práticas-políticas acolheram, desde então, a necessidade de se problematizar o status do conhecimento matemático, produto cultural de inúmeras disputas sociais em torno dos sentidos e dos significados de compreender e representar o mundo. Esses modos de compreender, representar, interagir e intervir no/com o mundo compõem sistemas complexos que, sob a perspectiva da Etnomatemática que adotamos, "incluem, invariavelmente, em todos os tempos e lugares no mundo, estratégias de observação, de comparação, de classificação, de avaliação, de 
Souza, U. \& Valle, J. (2020). Políticas curriculares para adiar o fim do mundo e poéticas sobre a existência na educação escolar indígena. Revista Latinoamericana de Etnomatemática, 13(1), 189-214. DOI: $10.22267 /$ relatem.20131.54

quantificação, de mensuração, representação, inferência e comunicação", conforme elucida D’Ambrosio (2020, p. 7, tradução nossa).

Assim como práticas de inspiração matemática - querendo nos remeter às estratégias mencionadas acima - vêm resolver os problemas relacionados no cotidiano de uma comunidade distinta com seus usos, costumes e tradições próprios passados de geração em geração, as perspectivas da Etnomatemática também contemplam e proporcionam uma ligação muito forte com relação ao cotidiano indígena, em que, por meio de observação e percepção da natureza que rodeia essa determinada cultura, pode-se prever inúmeros acontecimentos com o propósito de auxiliar e melhorar a vida no contexto e meio ambiente em que acontece o fato. Isso não é nenhuma mágica, mas sim a interação com o meio em que vivem. Desta maneira, ressaltamos também a relevância não somente das pesquisas-práticas-políticas inspiradas pela Etnomatemática, como também pelas etnociências, em geral.

Dentro desta perspectiva, trouxemos como proposta, neste trabalho, apresentar como foram pensadas as atividades da Aldeia/escola indígena a partir de um calendário cultural que rege todos os afazeres da comunidade, concretizado em sua inteireza desde que se iniciou o distanciamento social imposto por nossa condição sanitária, durante a pandemia. Tais atividades envolveram, por exemplo, criar um calendário escolar orientador e específico para a Educação Escolar Indígena em escolas jurisdicionadas pela Diretoria de Ensino da Região de São Vicente que contempla duas etnias: Tupi e Guarani M’byá. Cumpre-nos informar que, embora a construção do calendário, conforme mostraremos, já estivesse desde 2017, o contexto do isolamento proporcionou outras condições necessárias para que as crianças e os jovens aprendessem no/com o próprio território.

O trabalho pedagógico tem sido orientado pela fundamentação teórico-metodológica que o educador Paulo Freire (2012) construiu em torno do conceito de tema gerador, que tem encontrado, não poucas vezes (Domite \& Forner, 2014; Domite, 2014; Valle \& Santos, 2019), ressonância nas político-práticas educacionais no contexto da Educação Matemática. Torna-se relevante compreender como esse movimento se deu em relação à educação escolar indígena, inspirada por referenciais da Etnomatemática (D’Ambrosio, 2000, 2020; Domite, 2014; Costa \& Silva, 2010). Ao compreender o modo como se relacionam essas práticas-pesquisas-políticas, experimentadas e registradas neste 
trabalho, buscamos compartilhar também certos princípios que temos compreendido como imprescindíveis no território de disputas da política curricular e de suas implicações para os currículos de matemática - inegociáveis, em especial no período crítico por que passamos.

Valemo-nos dos graves aprendizados decorrentes da experiência ameaçadora da Pandemia em que nos encontramos para compreender o território das políticas curriculares como local privilegiado para os debates que ensejam diferentes, contraditórios e complexos, pontos de vistas, interesses e relações de poder desiguais. Nesse contexto, tratamos de possíveis e potenciais contribuições das práticas-políticas curriculares apresentadas para tensionar e desestabilizar as compreensões de currículo (e) de matemática, ao passo em que também apresentamos e discutimos político-práticas capazes de nos oferecer subsídios consistentes, necessários à resistência e à reinvenção curricular que propomos para quando "voltarmos" - "revoltarmos".

\section{A PANDEMIA É UM PEDIDO DE SILÊNCIO}

Há uma série de considerações, muitas certamente provisórias, sobre a pandemia e seus reflexos sobre nossas sociedades e, em particular, sobre a educação. Experimentar o trauma de não poder velar ou enterrar nossos mortos como fazíamos em um momento em que as mortes não param de aumentar, no Brasil como um todo, impacta substantivamente nossa subjetividade, fragilizando-a de diferentes maneiras.

Experimentamos, efetivamente, uma crise, no sentido que lhe dá a filósofa Hannah Arendt (2005), isto é, como um momento em que as respostas que formulamos ancoradas em nossos modos de ser/estar/sentir no/com o mundo - não respondem mais satisfatoriamente às perguntas que irrompem no presente. Com efeito, Arendt reconhece que a crise da autoridade na educação possui uma íntima relação com a crise da tradição - em nosso caso, crise da modernidade/colonialidade (Mignolo, 2017) -, o que não significa a ruptura de nosso vínculo com passado em si. Ao invés disso, Arendt (2005, p. 257) sugere que crise significa o momento em que "o fio da tradição está rompido, e temos de descobrir o passado por nós mesmos - isto é, ler seus autores como se ninguém os houvesse jamais lido antes". Com isto, não há, de fato, uma perda do passado, mas a possibilidade emancipatória da reinvenção de seus significados.

A filósofa sugere, ainda, a compreensão de que "estamos sempre educando para um mundo que ou já está fora dos eixos ou para aí caminha”, justamente porque, para ela, o 
Souza, U. \& Valle, J. (2020). Políticas curriculares para adiar o fim do mundo e poéticas sobre a existência na educação escolar indígena. Revista Latinoamericana de Etnomatemática, 13(1), 189-214. DOI: $10.22267 /$ relatem.20131.54

mundo, criado por mortais, se desgasta e pode assim tornar-se igualmente mortal (Arendt, 2005, p. 243). Portanto, "para preservar o mundo contra a mortalidade de seus criadores e habitantes, ele deve ser, continuamente, posto em ordem". Sob esta perspectiva, a questão que resume o problema da educação passa a ser "de que modo podemos educar a fim de que um por-em-ordem seja sempre possível?” (p. 244).

A crise, provocada pela Pandemia, remete-nos, portanto, à necessidade de buscar outras respostas, capazes de responder mais apropriadamente às questões e aos desafios que irrompem nesse novo contexto ou são agravados por ele, como é o caso da desigualdade social brasileira. Para nos dedicarmos à busca dessas outras respostas, no contexto de crise-oportunidade que a Pandemia proporciona, valemo-nos da leitura de referenciais que, como vêm fazendo o pesquisador indígena Aílton Krenak $(2019 ; 2020)$ e o sociólogo português Boaventura Sousa Santos (2020), compartilharam seus pontos de vista sobre as crises relacionadas tanto ao Covid-19 como também às suas causas. Sob a perspectiva daquele, consideramos relevante sublinhar que:

O vírus não mata pássaros, ursos, nenhum outro ser, apenas humanos. Quem está em pânico são os povos humanos e seu mundo artificial, seu modo de funcionamento que entrou em crise. É terrível o que está acontecendo, mas a sociedade precisa entender que não somos o sal da terra. Temos de abandonar o antropocentrismo; há muita vida além da gente, não fazemos falta na biodiversidade. Pelo contrário. Desde pequenos, aprendemos que há listas de espécies em extinção; Enquanto essas listas aumentam, os humanos proliferam, destruindo florestas, rios e animais. (Krenak, 2020, p.7)

A experiência que temos tido, atualmente, nos posiciona, segundo o mesmo autor, diante da iminência de nossa própria extinção ou, minimamente, uma substantiva ruptura em nosso modelo de vida, especialmente devido ao fato de que o planeta dá cada dia mais sinais de não suportar nossa demanda. Krenak (2020, p. 8) elucida que seja lá o que temos considerado como "humanidade", esse pacote "vai sendo descolado de maneira absoluta desse organismo que é a Terra, vivendo numa abstração civilizatória que suprime a diversidade, nega a pluralidade das formas de vida, de existência e de hábitos". Considerar o que vivemos como abstração civilizatória pode ensejar uma relevante chave de leitura para compreender a crítica feita, a que nos remeteremos adiante.

Afinal, caracterizar nosso modelo socioeconômico como abstração não é exclusividade de Krenak. Peter Stallybrass (2016, p. 40) afirma, nesse mesmo sentido, que aí reside o caráter contraditório do próprio capitalismo, isto é, "a sociedade mais abstrata que já 
existiu; uma sociedade que consome, o tempo todo, corpos humanos concretos. A abstração dessa sociedade é representada pela própria forma mercadoria". Compreender os significados e os sentidos mobilizados pela ideia de uma abstração civilizatória em curso, que nos faz vender o amanhã, sacrificá-lo, em nome de alguma comodidade que isso possa nos permitir hoje (Krenak, 2020). Ainda mais, compreendê-lo permite que possamos introduzir-nos à pandemia, que não se dá descolada desse contexto, mas nele e em decorrência dele.

No Brasil, em decorrência por exemplo dessa abstração civilizatória, tornou-se comum assistir discursos de políticos e grandes empresários em que afirmavam como implacáveis, certas e necessárias algumas milhares de mortes em nosso país ${ }^{3}$. Tais discursos, mobilizadores de práticas-políticas nefastas nesses tempos difíceis, ignoram o fato de que "a economia é uma atividade que os humanos inventaram e que depende de nós", ou, mais explicitamente, "se os humanos estão em risco, qualquer atividade humana deixa de ter importância" (Krenak, 2020, p. 10). Compartilhamos, por isso, a analogia elucidativa utilizada por Krenak (2020, p. 11) para tensionar e desestabilizar tais discursos: "Dizer que a economia é mais importante é como dizer que o navio importa mais que a tripulação”. Essa lógica, negligente, de abstração civilizatória, capaz de consumir/sacrificar nossos corpos concretos em nome de algo não-concreto, contudo, não é natural, mas socialmente construída, e tem sido compartilhada-imposta como se não houvesse alternativa.

A Etnomatemática nos inspira justamente a nos mobilizar contra essa abstração civilizatória, que se serviu e ainda se serve da matemática como sua espinha dorsal, no âmago de um discurso matematizado e altamente especializado. Inspiramo-nos em D’Ambrosio (1997, p. 107), por exemplo, quando o autor nos conta que:

A passagem do século XIX para o XX, simbolicamente representada na nova Babel, a Torre Eiffel - que expressa a fusão cultural sintetizada nos transportes rápidos e nas comunicações instantâneas -, glorifica a industrialização e o saber tecnológico, antecipando os assombrosos êxitos do porvir nas incursões pelo cosmos e no desvendar dos microcomponentes da matéria. Simbolicamente, abandona-se a humildade da busca em favor da arrogância do saber rigoroso, preciso e absoluto, sintetizado pela Matemática, então e hoje defendida como padrão de verdade incontestável e certeza definitiva. Torna-se lugar comum buscar a matematização como fator de validação em todos os setores do conhecimento. É esse o ideal máximo do racionalismo.

3 Os discursos do presidente Jair Bolsonaro têm sido os mais elucidativos da necropolítica praticada em seu governo (Mbembe, 2011). Fonte: https://www.gov.br/planalto/pt-br/acompanhe-oplanalto/noticias/2020/03/economia-nao-pode-parar-diz-bolsonaro-ao-setor-produtivo-brasileiro 
Souza, U. \& Valle, J. (2020). Políticas curriculares para adiar o fim do mundo e poéticas sobre a existência na educação escolar indígena. Revista Latinoamericana de Etnomatemática, 13(1), 189-214. DOI: $10.22267 /$ relatem.20131.54

Compreender o papel desempenhado pela matemática, como linguagem que estrutura o discurso científico e seu vil correspondente, o cientificismo, torna-se, sob essa perspectiva, necessário, porém ainda insuficiente para constituir o movimento contrahegemônico que desejamos mobilizar. Para constitui-lo, em especial no contexto da pandemia em que vivemos, acrescemos a contribuição da pesquisadora espanhola Yayo Herrero, que nos recorda de que:

A cultura ocidental, historicamente imposta ao resto do mundo através do comércio e da guerra, apresenta um importante defeito de origem: acreditando que nossa espécie e sua cultura estabam separadas do resto do mundo vivo e tinham maior valor. Ao contrário do que os povos originários continuam a defender, acreditamos que as pessoas possam viver além dos limites da natureza e independentemente da vulnerabilidade de ter corpos contingentes e finitos. Não nos sentimos parte dessa complexa rede de vida (Herrero, 2018, p. 78, tradução nossa)

Sob a perspectiva apresentada, somos conduzidos ao entendimento de que, em suas palavras, "a ficção de poder viver «emancipados» da natureza, de nosso próprio corpo ou do resto das pessoas constitui um eixo central do projeto civilizatório ocidental" (Herrero, 2018, p. 78, tradução nossa). Compreender em que medida o referido projeto civilizatório ocidental nos induz, desde nossa prática profissional até mesmo em nossa intimidade, ao esgotamento do planeta se faz necessário para que possamos considerar efetivamente que "somos seres radicalmente ecodependentes" (p. 82). Perceber-nos assim pode ajudar a compreender a abstração civilizatória mencionada por Krenak, cuja defesa incide na possibilidade de que:

O que estamos vivendo pode ser a obra de uma mãe amorosa que decidiu fazer o filho calar a boca pelo menos um instante. Não porque não goste dele, mas por querer lhe ensinar alguma coisa. "Filho, silêncio". A Terra está falando isso para a humanidade. E ela é tão maravilhosa que não uma ordem. Ela simplesmente está pedindo: "Silêncio". Esse é também o significado do recolhimento. (Krenak, 2020, p. 9, grifos nossos)

Imaginar a Pandemia como alegoria também foi um exercício realizado por Boaventura Sousa Santos (2020, p. 10) que afirma que "o sentido literal da pandemia do coronavírus é o medo caótico generalizado e a morte sem fronteiras causados por um inimigo invisível”. Considerar-nos uma espécie em extinção foi conclusão alcançada pela reflexão de Boaventura, mas também de Krenak, como vimos. Ambos, contudo, não aquiescem diante do horizonte que vislumbram se aproximar. Ao contrário disso, reconhecem na crise da pandemia a oportunidade de nos dedicarmos à busca de outras respostas. Boaventura Sousa Santos (2020, p. 7) menciona como possibilidade ontológica a formação de uma "consciência de comunhão planetária, de algum modo 
democrática", afinal até "a etimologia do termo pandemia diz isso mesmo: todo o povo". Estamos e somos tão ecodependentes e frágeis (Herrero, 2018) que um evento iniciado no fim de 2019 na China, em poucos meses, alterou drasticamente toda a nossa forma de nos relacionarmos, impondo-nos o isolamento e o distanciamento social como novas regras. Ignorar nossa ecodependência e a fragilidade de nossos corpos, lançandonos com maior rapidez nisso que Krenak chamou de abstração civilizatória, não nos ajudará a superar efetivamente a problemática em que esse mesmo estado de coisas nos inseriu.

Como, então, pensar a partir de nossa ecodependência e de nossa fragilidade para propor alternativas aos descaminhos da abstração civilizatória em que nos debatemos? Ainda é possível? Pode e, se sim, como a educação matemática contribuir? E as práticas-pesquisas-políticas inspiradas pela Etnomatemática, podem ajudar? Argumentamos, em consonância com as autores e os autores com quem temos dialogado, que é possível mobilizar práticas capazes de superar a mencionada abstração civilizatória, a partir do resgate de modos mais harmônicos de pensar/sentir/estar no/com o mundo - pressuposto mobilizado nas práticas-pesquisas-políticas inspiradas pela Etnomatemática.

Como os povos originários do Brasil lidaram com a colonização, que queria acabar com o seu mundo? Quais estratégias esses povos utilizaram para cruzar esse pesadelo e chegar ao século XXI ainda esperneando, reivindicando e desafinando o coro dos contentes? $\mathrm{Vi}$ as diferentes manobras que os nossos antepassados fizeram e me alimentei delas, da criatividade e da poesia que inspirou a resistência desses povos. A civilização chamava aquela gente de bárbaros e imprimiu uma guerra sem fim contra eles, com o objetivo de transformá-los em civilizados que poderiam integrar o clube da humanidade. Muitas dessas pessoas não são indivíduos, mas "pessoas coletivas", células que conseguem transmitir através do tempo suas visões sobre o mundo. Às vezes, os antropólogos limitam a compreensão dessa experiência, que não é só cultural. Eu sei que tem alguns antropólogos aqui na sala, não fiquem nervosos. Quantos perceberam que essas estratégias só tinham como propósito adiar o fim do mundo? (Krenak, 2019, pp. 28-29)

O excerto acima, que sintetiza parte do pensamento de Aílton Krenak, pode ser lido, no contexto deste trabalho, de, pelo menos, duas formas, que se complementam-articulam. A primeira delas sugere a fragilidade dos modos de compreensão antropológicos da experiência indígena e, por conseguinte, das comunidades tradicionais. A segunda delas, imediatamente conectada com a anterior, diz respeito à necessidade de compreendermos as estratégias mencionadas a partir de seu propósito de "adiar o fim do mundo". 
Souza, U. \& Valle, J. (2020). Políticas curriculares para adiar o fim do mundo e poéticas sobre a existência na educação escolar indígena. Revista Latinoamericana de Etnomatemática, 13(1), 189-214. DOI: $10.22267 /$ relatem.20131.54

Evidentemente, não se trata aqui de um mero descrédito à ciência e nem de "um fundamentalismo essencialista 'anticiência'", para utilizar a expressão de Santos (2007, p. 32) - ou mesmo “antimatemática”. A partir da percepção dos males causados por essa abstração civilizatória, calcada no cientificismo, o excerto anterior nos inclina, ao invés disso, à necessidade de se promover, como tem recomendado o mesmo sociólogo, uma ecologia dos saberes ou ainda "um uso contra-hegemônico da ciência hegemônica", isto é, a possibilidade de que "o saber científico possa dialogar com o saber laico, com o saber popular, com o saber dos indígenas, com o saber das populações urbanas marginais, com o saber camponês" (p. 32).

Longe de considerar que tais saberes tenham condições equânimes para o diálogo, Santos (2007, p. 33) afirma que "não há dúvida de que para levar o homem ou a mulher à Lua não há conhecimento melhor do que o científico; o problema é que hoje também sabemos que, para preservar a biodiversidade, de nada serve a ciência moderna". A menos de seus usos contra-hegemônicos, o autor acrescenta que a ciência moderna destrói a biodiversidade. Sob sua perspectiva, a ecologia de saberes implica o diálogo entre a ciência e outros saberes, "porque o que vem conservando e mantendo a biodiversidade são os conhecimentos indígenas e camponeses” (Santos, 2007, p. 33).

Em síntese, concordamos com o autor de que o conhecimento científico tem se mostrado eficaz quando nosso propósito consiste em levar o homem ou a mulher à lua, porém o mesmo não ocorre quando o propósito é assegurar a biodiversidade, necessária a nossa sobrevivência coletiva (e não somente a sobrevivência dos povos e comunidades tradicionais). Buscar estratégias, práticas e conhecimentos capazes de ensejar um projeto de adiamento do fim do mundo pressupõe a aceitação arendtiana de que "estamos sempre educando para um mundo que ou já está fora dos eixos ou para aí caminha" (Arendt, 2005, p. 243).

Assumir tais pressupostos, reconhecendo a gravidade de nossa situação, evidencia nossa responsabilidade social, de que não se desprende nossa responsabilidade individual, com a produção ativa desse estado global. Esse movimento corresponde também à atitude respeitosa e humilde de reconhecer quais de nossas escolhas, nenhuma delas prédeterminada, nos conduziram à forma social a que nos vemos impelidos hoje, em isolamento. Reconhecer que educamos para um mundo que já está fora dos eixos ou que em breve estará pode nos ajudar a perceber não somente nossa ecodependência e a 
finitude de nossos corpos, mas, principalmente, a necessidade de nos respaldarmos em outras formas de pensar/fazer/sentir mais solidárias, mais harmônicas, mais acolhedoras de nossa natureza interdependente.

Compreendendo como a escola, em especial a escola pública brasileira assim como as escolas indígenas, se posiciona e se desloca em meio à pandemia e às dificuldades originadas e/ou agravadas por ela, somos convocados também ao chamado para adiar o fim do mundo, inspirando-nos em perspectivas que, como a Etnomatemática, a reconheçam como espaço privilegiado de formação humana, democrático e popular, criativo e criador de experiências que refletem, cotidianamente, nossos limites e potenciais e, com maior ênfase, podem inspirar-se em nossa interdependência, que também é ecodependência, além de assumir a finitude de nossos corpos (Herrero, 2018) para conceber o que tem significado e, ao mesmo tempo, o que pode significar a educação escolar em nossa existência. Trata-se de uma escola inteiramente comprometida e responsável com/por um projeto emancipador de adiar o fim do mundo, até mesmo nos sentidos mais sutis que a expressão puder adquirir.

Posto isso, desejamos argumentar em favor da possibilidade de compreender as políticas curriculares, mobilizadas em diversos contextos entre distintos atores, como possíveis e potenciais ferramentas para adiar o fim do mundo. $O$ que pode contribuir para fortalecer, no território de disputa contraditório e complexo dos currículos (Arroyo, 2013), alternativas "capazes de manter nossas subjetividades, nossas visões, nossas poéticas sobre a existência" (Krenak, 2019, p. 33). Mantê-las vivas, circulando, faz sentido tanto no contexto de nosso projeto de adiar o fim do mundo dado que, como tem argumentado Santos (2007), tais saberes e subjetividades nos oferecem muitos indícios sobre como construir modos mais harmônicos de ser/estar no/com o planeta, cheios da consciência de nossa finitude, de nossas fragilidades de nossa eco e interdependência.

Para atingir essa finalidade, compartilhamos em seguida projetos e processos que consideramos relevantes e animados pelo referencial freireano, no campo da política curricular, por entendê-los como capazes de contribuir para pensarmosfazermos sobre as políticas curriculares, em especial no que se refere à educação escolar indígena no contexto da pandemia.

\section{UM CASO DE POLÍTICAS CURRICULARES SOBRE A EXISTÊNCIA NA EDUCAÇÃO ESCOLAR INDÍGENA}


Souza, U. \& Valle, J. (2020). Políticas curriculares para adiar o fim do mundo e poéticas sobre a existência na educação escolar indígena. Revista Latinoamericana de Etnomatemática, 13(1), 189-214. DOI: $10.22267 /$ relatem.20131.54

Conforme antecipamos, apresentaremos como foram pensadas as atividades da Aldeia/escola indígena a partir de um calendário cultural que rege todos os afazeres da comunidade. Tais atividades envolveram, por exemplo, criar um calendário escolar orientador e específico para a Educação Escolar Indígena em escolas jurisdicionadas pela Diretoria de Ensino da Região de São Vicente que contempla duas etnias: Tupi e Guarani M’byá.

Durante o processo de construção de um calendário específico, o trabalho pedagógico tem sido orientado pela fundamentação teórico-metodológica que o educador Paulo Freire (2012) construiu em torno do conceito de tema gerador.

De acordo com a Resolução SE 147, de 29-12-20034, que ampara a educação escolar indígena, fica evidenciado a autonomia das comunidades indígenas na elaboração do próprio calendário escolar. Diante dessa informação, no ano de 2016 foram realizadas oficinas nas oito escolas e salas vinculadas que pertencem à região, com o intuito de unificarmos um calendário que amparasse a realidade das etnias. Quatro anos após a elaboração deste calendário específico para educação escolar indígena as unidades escolares tem a oportunidade de efetivamente colocá-lo em prática, devido ao isolamento ao qual se encontram e a oportunidade de ter o docente, em sua maioria, pertencentes a própria comunidade.

Para que seja possível compreender teórico-metodologicamente como se espera que opere com o conceito de tema gerador, remetemo-nos à perspectiva da educadora Maria do Carmo Santos Domite que, no decorrer de uma entrevista cedida a Régis Forner, afirma, sobre a ação pedagógica via tema gerador:

Era esperado que o caminho do ensinar e do aprender fosse mais ou menos por etapas como: partir de um tema eleito pela comunidade escolar e/ou grupo em sala de aula - por isso, em geral, fora do terreno de uma disciplina propriamente escolar -, problematizar tal tema junto aos alunos, levando-os a formular questões e, a partir das questões formuladas, desenvolver os conhecimentos ditos escolares. (Forner \& Domite, 2014, p. 160)

O ensino de matemática via tema gerador, portanto, torna-se também um elemento fundamental para ser estudado como potencial relação das particularidades do conhecimento matemático com os pressupostos da pedagogia crítica de Freire, assim como sua mobilização em uma política curricular. Trata-se, afinal, de uma proposta cujo objetivo consiste em romper a dissociação, já instalada, entre conhecimento e cotidiano,

4 O texto da Resolução, na íntegra, pode ser encontrado no seguinte endereço: http://siau.edunet.sp.gov.br/ItemLise/arquivos/147_03.HTM?Time=06/07/2020\%2022:46:19 
como se os aprendizados da escola não extrapolassem seus muros. Aqui, a análise das contradições vivenciadas na realidade local são fundamentais como disparadores do estudo escolar, dado, sobretudo, que o conhecimento escolar será visto como ferramenta de desvelamento e de intervenção dessas/nessas contradições

Em sua obra prima, Pedagogia do Oprimido, Freire (2012, p. 125) afirma que todo indivíduo oprimido vive "uma relação dialética entre seus condicionamentos e sua liberdade". Diante disso, homens e mulheres também se contradizem, diz o educador, posicionando-se, muitas vezes, em favor da manutenção das estruturas que os oprimem. Por isso, em sua obra, há a defesa fundamental de que tais temas sejam disparadores, geradores, do estudo escolar - contando, para isso, com a contribuição dos saberes provenientes de diferentes disciplinas, capazes de lançar luz não somente sobre as contradições vivenciadas, mas também de proporcionar a construção de caminhos possíveis para sua superação. O papel social da escola é ressignificado no sentido de que seja possível pensar nos conteúdos escolares a partir do lugar social experimentado por cada grupo, razão pela qual tais conhecimentos passam a estar vinculados a problemas enfrentados pela comunidade escolar - que a impossibilitam de ser mais, vocação ontológica de todo ser humano, como defende Freire (2012) em sua Pedagogia do Oprimido.

Em nosso caso, da Diretoria de Ensino da Região de São Vicente, para iniciar as atividades com os alunos, foi dada ênfase a dois importantes temas geradores - Plantio e Procriação dos animais - que permitem explorar a cultura indígena orientando o trabalho pedagógico na direção do reconhecimento, da valorização e consequente fortalecimento da dessas culturas. Utilizando a figura abaixo, buscamos representar as possíveis/potenciais correlações entre as disciplinas que estruturam a Educação Básica e temáticas constituídas a partir do trabalho com o tema gerador de Procriação de Animais: 


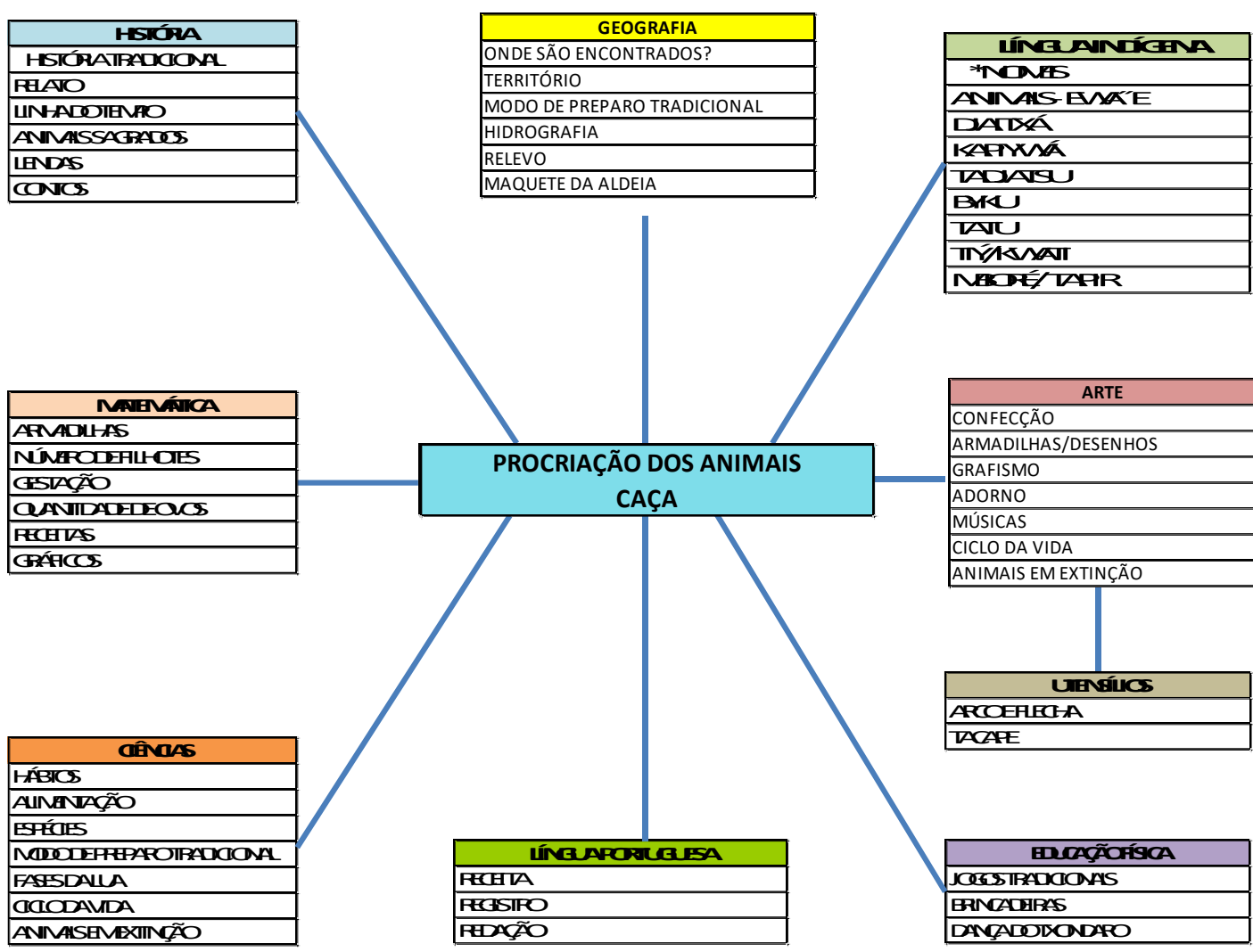

Figura 1: Organização curricular via tema gerador.

Fonte: Acervo dos autores)

É interessante ressaltar o papel das disciplinas nesse movimento de integração curricular pela via do tema gerador. Afinal, as disciplinas jogavam papeis diferentes na construção de uma leitura menos fragmentada da realidade em que as comunidades escolares estavam imersas. Matemática, ciências, história, geografia e outras colaboravam mutuamente tanto com o entendimento de determinado obstáculo imposto à vivência daqueles indivíduos como também com a reflexão sobre os possíveis caminhos de sua superação. A esse mesmo respeito, consideremos ainda:

Daí que, partindo dos temas geradores sugeridos pelo estudo de realidade que antecede à construção curricular, propicia-se um olhar multifacetado da realidade. É como se o fenômeno ou situação fossem vistos através de uma lente que os decompõe segundo as diferentes luzes do conhecimento (física, química, biologia, história, geografia, artes etc.), permitindo revelar aspectos fragmentados da realidade. Estes, integrados, permitem melhor compreensão daquele fenômeno ou situação. (Delizoicov \& Zanetic, 1993, p. 13)

Após a discussão desses dois temas geradores, que já são do cotidiano das comunidades, orientamos os docentes na perspectiva de sala de aula, a fim de adaptar essas situações de aprendizagem para que sejam desenvolvidas as atividades com os alunos, garantindo, 
de fato, o tão sonhado ensino diferenciado, isto é, capaz de reconhecer os saberesfazeres e os contextos de origem como interlocutores indispensáveis no processo educativo.

Outra ação que destacamos como parte da política curricular, dando ensejo e enredo às demais, foi feita com os Professores Coordenadores de Núcleo Pedagógico - Equipe responsável pela Educação Escolar Indígena, corpo docente e membros da comunidade. Compondo um atendimento a quase duzentos alunos, a Diretoria de Ensino São Vicente possui oito (8) Escolas Indígenas e sete (7) salas vinculadas. Com essa abrangência, a região possui duas etnias a Tupi e a Guarani M’byá . Visando elaborar um calendário escolar que respeite e valorize a especificidade das etnias, bem como o fortalecimento cultural, foi desenvolvido um calendário específico, conectado aos afazeres cotidianos das comunidades. A princípio seriam elaborado dois calendários, um para etnia Tupi e outro para etnia Guarani. Porém, como são etnias irmãs e vivem na mesma região, foram realizadas oficinas com professores e membros das comunidades e diagnosticouse que os conhecimentos tradicionais, práticas e táticas de sobrevivência são convergentes, não necessitando haver dois calendários. Desta forma, elaborou-se um único calendário contemplando todas as escolas indígenas da nossa diretoria, conforme Anexo I.

O Calendário elaborado contempla as atividades como plantio, colheita, procriação de animais, também apresenta as fases lunares influenciando nas atividades do calendário, embora este material apresente diferença em relação a calendários não indígenas permanece a garantia de 200 dias letivos, sem haver prejuízo da aprendizagem dos alunos, fortalecendo a cultura dessas comunidades. Os temas geradores, podem ser articulados de diversas maneiras, podendo transpassar pelas diversas áreas do conhecimento. E podem ser trabalhados em conjunto com as atividades representadas no calendário, como no exposto anteriormente na figura do tema Procriação dos animais e caça.

Para caracterizar ainda mais a política curricular que está em curso, acrescentamos, a seguir, a experiência realizada no contexto da Escola Estadual Indígena Tangará, com alunos e alunas do $6^{\circ}$ ano do Ensino Fundamental II, com a professora Paula Aparecida Baptista e tendo "Arco e flecha" como tema gerador:

\section{CIÊNCIAS DA NATUREZA E MATEMÁTICA}

(Disciplinas: Ciências e Matemática) 
Souza, U. \& Valle, J. (2020). Políticas curriculares para adiar o fim do mundo e poéticas sobre a existência na educação escolar indígena. Revista Latinoamericana de Etnomatemática, 13(1), 189-214. DOI: $10.22267 /$ relatem.20131.54

Ciências:

Saber qual lua é a correta para a extração da matéria prima para confecção do arco e flecha.

Neste momento, explicar aos alunos que existe um dia certo para serem extraídas as matérias primas. Explicar que de acordo com o conhecimento tradicional Tupi/ Guarani as matérias primas devem ser extraídas exclusivamente na Lua Minguante para evitar a proliferação de insetos que deterioram a mesma.

Logo em seguida fazer junto com eles uma lista das matérias primas que serão utilizadas para confeccionar cada parte do utensílio.

Matérias primas:

- Madeira para fazer o arco, neste caso a Brejaúva ou o Brejauvú.

- Embira para fazer a corda. Explicar que a fibra a ser usada é extraída de uma madeira chamada Imbirussú, e que a parte utilizada é a casca desta árvore, se possível extrair junto com eles acompanhado de um detentor deste saber.

- Extrair com eles as palhas que serão usadas na confecção do adorno no utensílio.

- Conhecer tipos de solo.

- Ecossistema.

Matemática:

Mostrar ao aluno as diversas formas de associar a matemática ao utensílio a ser confeccionado, desde a ida à mata para buscar a matéria prima, até a sua confecção.

- O uso dos números (quantidade, ordem, medida e código);

- Formas geométricas espaciais (cubo, esfera, paralelepípedo, cone. Prisma de base triangular e pirâmide);

- Tecelagem (palha e Cipó)

Fonte. Acervo dos autores.

No ano de 2017, colocou-se em prática o calendário unificado como Projeto Piloto em duas escolas indígenas para serem acompanhadas periodicamente. Em virtude do sucesso desta ação, o calendário foi implementado nas demais escolas ao longo do ano de 2018. Mas de fato está sendo testado-desafiado e colocado em prática em meio à pandemia, onde o isolamento social se faz necessário para evitarem a contaminação pelo Covid-19, porém, o cotidiano das aldeias onde o ensino aprendizagem acontece não para, proporcionado a continuidade dessas troca de saberes.

Essa proposta foi importante para auxiliar nas atividades escolares e na construção do currículo diferenciado que ampare as especificidades em torno da Educação Escolar Indígena Tupi e Guarani da nossa região, esperando formar um aluno que consiga se expressar diante de todas as situações que os cercam, seja dentro da comunidade ou fora dela, fortalecendo a identidade indígena e, ao mesmo tempo, praticando a alteridade. 


\section{POÉTICAS CURRICULARES ${ }^{5}$ EXISTENTES E RESISTENTES PARA ADIAR O FIM DO MUNDO}

A partir da experiência realizada nas escolas indígenas jurisdicionadas sob a Diretoria de Ensino da Região de São Vicente, tecemos, adiante, alguns comentários que nos parecem indicativos relevantes sobre as possibilidades de conceber a política curricular de matemática, quando inspiradas pelas perspectivas socioculturais da Educação Matemática e, em particular, pela Etnomatemática. Reivindicamos e argumentamos em favor do direito de, valendo-nos dessas práticas-políticas-pesquisas, construir currículos culturalmente relevantes, capazes de, como dissemos, fortalecer a identidade indígena na medida em que se pratica a alteridade como princípio.

Com efeito, parte de nossa argumentação reside na percepção de que a política, "que devia ser a mediadora entre as ideologias e as necessidades e aspirações dos cidadãos, tem vindo a demitir-se dessa função" (Santos, 2020, p. 10). Com a política curricular, em especial a política curricular nacional, se passa o mesmo. As político-práticas prescritivas, centralizadas e homogêneas, "políticas do conhecimento oficial", para utilizar a expressão do curriculista estadunidense Michael Apple (2011), se demitem, sistemática e historicamente, dessa função mediadora entre ideologias, necessidades e aspirações dos cidadãos.

Acrescemos, ainda, o fato de que Boaventura Sousa Santos $(2007 ; 2020)$ tem afirmado que há, em curso, a contração do presente - resultado também de vendermos nosso amanhã a qualquer preço (Krenak, 2020) -, isto é, a redução de toda a diversidade que habita a realidade a alguns tipos de realidade, que o autor considera muito concretos, limitados e reduzidos. Ora, a contração do presente também se torna perceptível nas políticas curriculares que, incapazes de reconhecer essa diversidade, reduzem-na à política do conhecimento oficial, em que os mesmos grupos hegemônicos ditam quais são os conhecimentos válidos, oficiais, acumulados por uma humanidade de que poucos, autoproclamados, fazem parte (D’Ambrosio, 2020). Santos (2020, p. 28) reageresponde à contração do presente por meio da Sociologia das Ausências, que entende

5 Valemo-nos aqui, inclusive, da ideia de Poéticas Públicas em Gravatá \& Oliveira (2019) que, inspirados pelo movimento da Virada Educação, nos proporcionam propósitos muito interessantes para pensarmos as práticas-políticas-pesquisas curriculares: interromper a suposta normalidade como poética pública da cidade, inaugurar atos de intimidade com o que existe e incorporar a habilidade de não se acostumar com as distâncias. 
Souza, U. \& Valle, J. (2020). Políticas curriculares para adiar o fim do mundo e poéticas sobre a existência na educação escolar indígena. Revista Latinoamericana de Etnomatemática, 13(1), 189-214. DOI: $10.22267 /$ relatem.20131.54

"que muito do que não existe em nossa realidade é produzido ativamente como não existente, e por isso a armadilha maior para nós é reduzir a realidade ao que existe". Posicionando-nos em diametral oposição às ausências construídas, representantes dessa "racionalidade preguiçosa, que realmente produz como ausente muita realidade que poderia estar presente" (Santos, 2020, p. 20), dedicamo-nos à crítica do modo como as políticas curriculares oficiais têm sistematicamente invisibilizado, construindo como ausentes, os currículos pensadospraticados ${ }^{6}$, as práticas cotidianas emancipatórias (Oliveira, 2013), os inéditos-viáveis (Freire, 2012), tão necessários à emancipação. Mas, mais que isso, insistimos, como faz a pesquisadora negra Nilma Lino Gomes (2017, p. 61) na necessidade do "exercício de construção epistemológica de uma pedagogia das ausências e das emergências como possibilidade de abrir espaço para novas racionalidades, reflexões e inquietações educacionais, sobretudo na escola". Para a educadora, esse exercício de construção epistemológica se relaciona diretamente com o estímulo, o registro e o compartilhamento de "práticas inconformistas, desestabilizadoras e rebeldes" (Gomes, 2017, p. 119). O conflito, ensejado por tais práticas, desempenha um relevante papel no sentido de desestabilizar e vulnerabilizar discursos-políticas-práticas que permitam que os ausentes sejam ativamente produzidos dessa forma.

Propor um exercício constante de construção epistemológica de uma pedagogia das ausências e das emergências, como faz Nilma Lino Gomes (2017), nos inclina, enfim, não somente à crítica dos discursos-políticas-práticas que reduzem existências e diferenças à ausências, mas também, e principalmente, ao movimento de substituir isso que foi produzido como ausência por existência ativa, cidadã, democrática e crítica. Engajamo-nos, assim, num exercício de desinvisibilizar o que, no campo das políticas curriculares, foi produzido como inexistente, ausente, isto é, múltiplas e diferentes capacidades criativas, criadoras e críticas de pensarfazer currículo, em especial de matemática, inspirados pela Etnomatemática. Convergimos, portanto, para o entendimento da pesquisadora cotidianista Inês Barbosa de Oliveira:

6 "A expressão currículos pensadospraticados foi recentemente criada com o objetivo de deixar clara a indissociabilidade que entendemos existir entre prática e teoria, entre reflexão e ação. Assim, substituímos o termo currículos praticados, anteriormente utilizado, por esse. Isso porque entendemos que existe, no cotidiano das escolas, uma criação cotidiana de currículos pelos professores e alunos nas salas de aula, gerada a partir do diálogo entre referenciais e reflexões teóricas, possibilidades e limites concretos de cada circunstância e da articulação entre as múltiplas redes de sujeitos e de conhecimentos presentes nas escolas". (Oliveira, 2013, pp. 3-4) 
O desenvolvimento cotidiano de práticas participativas e solidárias em todos os espaços estruturais nos quais estamos inseridos, bem como a busca de ampliação de sua institucionalidade, assumem, nesse sentido, importância capital na tessitura da emancipação social. As práticas pedagógicas desenvolvidas nessa perspectiva, pela importância que possuem na formação das subjetividades daqueles que delas participam, aparecem, portanto, como fundamentais nessa compreensão. Desinvisibilizá-las, como pretende a Sociologia das Ausências, torna-se fundamental. Considerar sua pluralidade, heterogeneidade e impossível aprisionamento em modelos do que deveriam ser as práticas emancipatórias também. Nesse sentido, o reconhecimento e valorização dos múltiplos currículos pensadospraticados, inventados pelos praticantes dos cotidianos escolares, permitem, também, afastarmo-nos da ideia moderna e individualista de emancipação, que a percebe como uma conquista definitiva, um "lugar" a se chegar, no futuro, uma "Terra Prometida" à qual cada um chegará, ou não, em função de suas próprias virtudes, aprendizagens e esforços. (Oliveira, 2013, p. 12)

Compreender as possibilidades inauguradas nos currículos e nos cotidianos das escolas indígenas jurisdicionadas à Diretoria de Ensino da Região de São Vicente, por meio da utilização dos temas geradores, da construção de um calendário específico e das atividades realizadas com alunas e alunos pode, nesse sentido, estimular a busca por mais e mais práticas participativas e solidárias, emancipatórias em muitos e diferentes sentidos. Quantas outras práticas-políticas permanecem invisibilizadas por políticas curriculares incapazes de reconhecê-las ou de reconhecer nelas seu potencial emancipatório? Invisibilizá-las corresponde a produzi-las como ausentes, inexistentes, de que decorre nosso indiscutível compromisso com desinvisibilizar tais práticas, argumentando em favor de sua permanência no horizonte da realidade. Nesse caso, os referenciais da Etnomatemática, nos ajudam a concluir que esses currículos pensadospraticados, reais, possíveis e potenciais, contêm e mobilizam práticas-políticas construídas em contextos plurais e multiculturais, em que distintas "estratégias de observação, de comparação, de classificação, de avaliação, de quantificação, de mensuração, representação, inferência e comunicação" (D’Ambrosio, 2020, p. 7, tradução nossa), como já mencionado, se articulam enredadas por essas culturas que estabeleceram com o mundo formas muito mais harmônicas e respeitosas de coexistência.

São modos existentes e resistentes de maior conexão com o mundo que habitamos. Desinvisibilizá-los, portanto, representa uma alternativa possível de demonstrar sua existência, a despeito dos discursos-práticas-políticas que insistem em invisibilizá-los, negligenciando sua existência e suas potenciais contribuições à reflexão curricular. 
Considerando os currículos como tudo aquilo que se passa nas escolas, envolvendo os conteúdos formais de ensino, relações sociais, manifestações culturais e conjuntos de conhecimentos não escolares; entendendo, ainda, que todos esses aspectos estão impregnados de relações sociais, epistemológicas e culturais de caráter mais global, a discussão proposta visa a evidenciar os modos pelos quais alguns dos princípios da emancipação social (...) contribuem para a reflexão curricular fornecendo elementos potencializadores de compreensão ampliada das questões e soluções que envolvem os currículos pensadospraticados nos diferentes cotidianos escolares. (Oliveira, 2013, p. 3)

A pesquisadora contribui, não somente ampliando a concepção de currículo, convergente à de Freire (2012), mas principalmente por meio da reflexão curricular realizada em interlocução direta com a obra de Boaventura Sousa Santos. Essa reflexão nos convoca à necessidade de compreender, mais do que a noção de conhecimentoemancipação, que também nos ajuda a compreender como socialmente relevantes as práticas-políticas descritas neste trabalho, a ideia de que "quanto mais globais forem os problemas, mais locais são as soluções" (Oliveira, 2013; Santos; 2007). Em nosso contexto vivido, propriamente dito, compreender a afirmação de Santos, também citada por Oliveira, significa, em particular, que solucionar a Pandemia, que constitui um problema global, demanda de nós atitudes e iniciativas locais. O engajamento nas práticas-políticas-pesquisas que se dedicam a desinvisibilizar os currículos pensadospraticados, nos quais encontramos enredadas diversas práticas socioculturais, inclusive emancipatórias e solidárias, converte-se, assim, num processo permanente de "repolitização global da prática social, com o reconhecimento do caráter político dos diferentes espaçostempos de inserção social" (Oliveira, 2013, p. 14). A repolitização global da prática social, que nos inspira à desinvisibilizar currículos pensadospraticados, pode ensejar, portanto, políticas curriculares para adiar o fim do mundo, desde que recordemos que, aqui, adiar o fim do mundo significa também manter vivas as subjetividades indígenas, suas visões e suas poéticas sobre a existência (Krenak, 2019), ilustradas na experiência das escolas indígenas de que tratamos.

\section{CONSIDERAÇÕES FINAIS}

Se nossa prática pedagógica não se resume à educação bancária que Freire (2012) tanto criticou, então propomos, em seu lugar o seu revés, isto é, a educação problematizadora, emancipatória, democrática, aberta e disponível ao diálogo e à escuta, que não se constrói sob a prescrição curricular, mas sob outro paradigma, como temos discutido em trabalhos anteriores (Valle \& Santos , 2019; Valle 2020). Porém, professoras e 
professores, em todas as etapas e modalidades da Educação Básica brasileira constroem cotidianamente práticas que concretizam tais ideais, corporificando-os. Desinvisibilizar práticas emancipatórias reais, já em curso, mapeá-las, compartilhá-las, torná-las práticas públicas, de maneira que possam subsidiar outras consiste em uma das múltiplas e variadas possibilidades de ação nesse sentido. Por isso, dedicamo-nos, neste trabalho, a resgatar e discutir uma experiência curricular na educação escolar indígena, capaz de nos oferecer subsídios bastante importantes sobre como podemos mobilizar currículos pensadospraticados inspirados pela Etnomatemática, que pode informar e orientar políticas-práticas-pesquisas no âmbito da Educação Matemática de maneira a considerar a necessidade de se preocupar tanto com a identidade como também com a alteridade em seus processos formativos.

A experiência descrita está, ainda, enredada às práticas-pesquisas-políticas que têm sido colocadas em debate por meio de estudos como este pelo Grupo de Estudos e Pesquisa em Etnomatemática, o GEPEm, na esteira da inversão do vetor nas políticas curriculares (Valle \& Santos, 2019; Valle, 2020), fazendo referência à experiência de Freire como Secretário de Educação de São Paulo e sua política curricular de matemática; ou ainda Conrado (2019), que se dedicou à discussão da política curricular de matemática no contexto de um Centro Integrado de Educação de Jovens e Adultos, Cieja que participa do Programa Transcidadania, destinado ao acolhimento da população LGBTT, em especial, travestis e transexuais, em situação de vulnerabilidade. Nesse enredo, consideramos, dentre tantas outras contribuições, os estudos de Costa e Silva (2010, p. 259), que nos chamam a atenção para que busquemos "um maior conhecimento sobre as etnomatemáticas negras e indígenas evidenciando o silenciado, o desconhecido e os mecanismos de dominação e de exploração entre grupos etnoculturais que estão presentes na sociedade brasileira, na escola e, também, no ensino de matemática”.

A professora da escola pública Valdirene Rosa de Souza (2020), membro-pesquisadora negra do GEPEm apresenta-nos também seus currículos pensadospraticados inspirados na Etnomatemática, demonstrando possibilidades para pensarfazer o currículo de matemática, considerando contribuições das culturas negras. Na esteira dessa e de tantas outras pesquisas-práticas-políticas mobilizadas pelo GEPEm, sob a orientação da professora Maria do Carmo Santos Domite, incluímos esta, a experiência das escolas indígenas jurisdicionadas sob à Diretoria de Ensino da Região de São Vicente, 
Souza, U. \& Valle, J. (2020). Políticas curriculares para adiar o fim do mundo e poéticas sobre a existência na educação escolar indígena. Revista Latinoamericana de Etnomatemática, 13(1), 189-214. DOI: $10.22267 /$ relatem.20131.54

organizando a experiência escolar indígena a partir de elementos tanto da Etnomatemática como também da contribuição de Freire (2012), por meio do conceito do tema gerador. Cumpre-nos dizer, inclusive, que Domite fora formadora do professor Ubiratã Gomes, em sua Formação Intercultural Superior do Professor Indígena, quando lhe ensinou sobre o conceito de tema gerador, experimentado pela autora conforme registrado em Forner \& Domite (2014) e em Valle \& Santos (2019); Valle, 2020). Essas redes, de que nos fala Oliveira (2013), vão nos mostrando a riqueza dos currículos pensadospraticados, reais, experimentados para pensarmos, inclusive, a matemática como relacional, cultural, “frágil e falível”, para nos remetermos a Paul Ernest (1991) ou, minimamente, humana demais.

Domite nos ensinou sobre como adiar o fim do mundo, porque dedicava, a nós, seus orientandos e ao mundo, o mesmo afeto, tecendo com delicadeza e cuidado redes de que nos permitiriam, autores, nos encontrar, cerca de cinco anos após seu falecimento, para registrar essa experiência em curso em XX escolas indígenas e salas vinculadas, das etnias Tupi e Guarani, valendo-se do conceito de tema gerador, e discuti-la como uma experiência de rica inversão do vetor nas políticas curriculares, inclusive de matemática. Com anos de sua prática e de seu exemplo, Domite nos ensinou que uma escola comprometida com o adiamento do fim do mundo sempre será aquela que toma com alegria a experiência da existência humana, que vê potencial mesmo na finitude de nossos corpos, que nos explica sobre nossa interdependência, de modo que possamos "ser mais", para utilizar uma expressão freireana, que encerra nela sentidos possíveis de nossa emancipação - e que recusemos "nossa" emancipação, quando "nossa" representar apenas $^{7}$ a espécie humana. Essa escola pode considerar sempre a possibilidade de interlocução com práticas culturais, inclusive com aquelas que foram produzidas em contextos distintos, tomando seus praticantes como interlocutores, pois aprendemos no diálogo com tais práticas - não só matemática, evidentemente, mas também matemática - modos de adiar o fim do mundo.

7 Representamos muito pouco de toda biodiversidade do planeta: A vida humana é uma ínfima parte $(0,01 \%)$ da vida planetária a defender (Santos, 2020, p. 23). 


\section{REFERÊNCIAS}

Apple, M. (2011). A política do conhecimento oficial: faz sentido a ideia de um currículo nacional? En Moreira, A. \& Silva, T. (eds.). Currículo, cultura e sociedade (pp. 71-106). São Paulo: Cortez.

Arendt, H. (2005). Entre o passado e o futuro. São Paulo: Perspectiva.

Arroyo, M. (2013). Currículo, território em disputa. Petrópolis: Vozes.

Brasil. (1988). Constituição da República Federativa do Brasil. Brasília/DF: Senado Federal/Centro Gráfico.

Brasil. (1996). Lei de Diretrizes e Bases da Educação - Lei Federal no 9.394 de 1996. Recuperado de: http://www.planalto.gov.br/ccivil_03/leis/19394.htm

Cardoso, A. (2020). Covid-19 e indígenas: os desafios no combate ao novo coronavírus. Recuperado de: https://www.uol.com.br/vivabem/noticias/redacao/2020/05/02/covid-19-eindigenas-os-desafios-no-combate-ao-novo-coronavirus.htm

Colombini, G. (2019). Colônia. Rio de Janeiro: Editora GLAC.

Conrado, A. (2019). Diversidade, diferença e currículo de matemática: relações entre macropolíticas e o tempo dos atores na escola. (Tesis doctoral) Universidade de São Paulo, São Paulo.

Costa, W. \& Silva, V. (2010). A desconstrução das narrativas e a reconstrução do currículo: a inclusão dos saberes matemáticos dos negros e dos índios brasileiros. Educar em Revista (Impresso), pp. 245-260.

D'Ambrosio, U. (1997). Transdisciplinaridade. São Paulo: Palas Athena.

D'Ambrosio, U. (2000). Sociedade, cultura, matemática e seu ensino. Revista Educação e Pesquisa, 31, pp. 99-120.

D'Ambrosio, U. (2020). Ethnomathematics: past and future. Revemop, 2, pp. 1-14.

Delizoicov, D. \& Zanetic, J. (1993). A proposta de interdisciplinaridade e o seu impacto no ensino municipal de $1^{\circ}$ grau. En: Pontuschka, N. (ed.). Ousadia no diálogo: interdisciplinaridade na escola pública (pp. 9-18). São Paulo: Edições Loyola.

Domite, M. (2014). Na trilha da etnomatemática: alteridade e escuta em Freire. Conferencia presentada en el: Encontro de Etnomatemática do Rio de Janeiro, 1, pp. 37-50. Rio de Janeiro: Anais do EEtnomat-RJ.

Domite, M. \& Forner, R. (2014). Um encontro entre Paulo Freire e a educação matemática: Maria do Carmo Domite instigada por Régis Forner. Revista Internacional de Educación para la Justicia Social (RIEJS), 3 (1), pp. 157-172.

Ernest, P. (1991). The philosophy of mathematics education. Abingdon: Routledge Falmer.

Freire, P. (2012). Pedagogia do Oprimido. São Paulo: Paz e Terra. 
Gomes, N. (2017). O movimento negro educador: saberes construídos nas lutas por emancipação. Petrópolis: Vozes.

Gravatá, A. \& Oliveira, A. (2019). Poéticas públicas. São Paulo: Edição dos Autores.

Herrero, Y. (2018). Sujetos arraigados en la tierra y los cuerpos: hacia una antropología que reconozca los límites y la vulnerabilidad. Recuperado de: https://www.museoreinasofia.es/sites/default/files/actividades/programas/

Kehl, M., Gomes, U. \& Takuá, C. (2016). Violação de direitos humanos dos povos indígenas no Relatório da Comissão da Verdade. Recuperado de: http://www.rededosaber.sp.gov.br/Videoteca/DadosBloco.aspx?id_bloco=2086

Krenak, A. (2019). Ideias para adiar o fim do mundo. São Paulo: Companhia das Letras.

Krenak, A. (2020). O amanhã não está à venda. São Paulo: Companhia das Letras.

Mbembe, A. (2018). Necropolítica: biopoder, soberania, estado de exceção, política da morte. São Paulo: N-1 Edições.

Mignolo, W. (2017). Desafios decoloniais hoje. Epistemologias do Sul, 1 (1), pp. 12-32.

Nóvoa, A. (2020). Webconferência. Recuperado de: https://www.youtube.com/watch?v=ef3YQcbERiM

Oliveira, I. (2013). Contribuições de Boaventura de Sousa Santos para a reflexão curricular: princípios emancipatórios e currículos pensadospraticados. Revista ecurriculum, 8 (2), pp. 2-22.

Santos, B. (2007). Renovar a teoria crítica e reinventar a emancipação social. São Paulo: Boitempo.

Santos, B. (2020). A cruel pedagogia do vírus. Coimbra: Almedina.

Souza, V. (2020). Outros saberes e práticas matemáticas em sala de aula. VEm Brasil. Recuperado de: https://www.youtube.com/watch?v=jv2YX8c4xK0

Stallybrass, P. (2016). O casado de Marx: roupa, memória, dor. Belo Horizonte: Autêntica Editora.

Valle, J. (2020). O resgate da escola pública utópica de Freire como possibilidade inscrita na história: o Movimento de Reorientação Curricular em São Paulo (1989-1992). REMATEC, 15 (33), pp. 201-223.

Valle, J. \& Santos, V. (2019). Interver o vetor do currículo: o Movimento de Reorientação Curricular de Freire em debate. Revista e-Curriculum, 16 (4), pp. 1207-1233. 


\section{Anexo I}

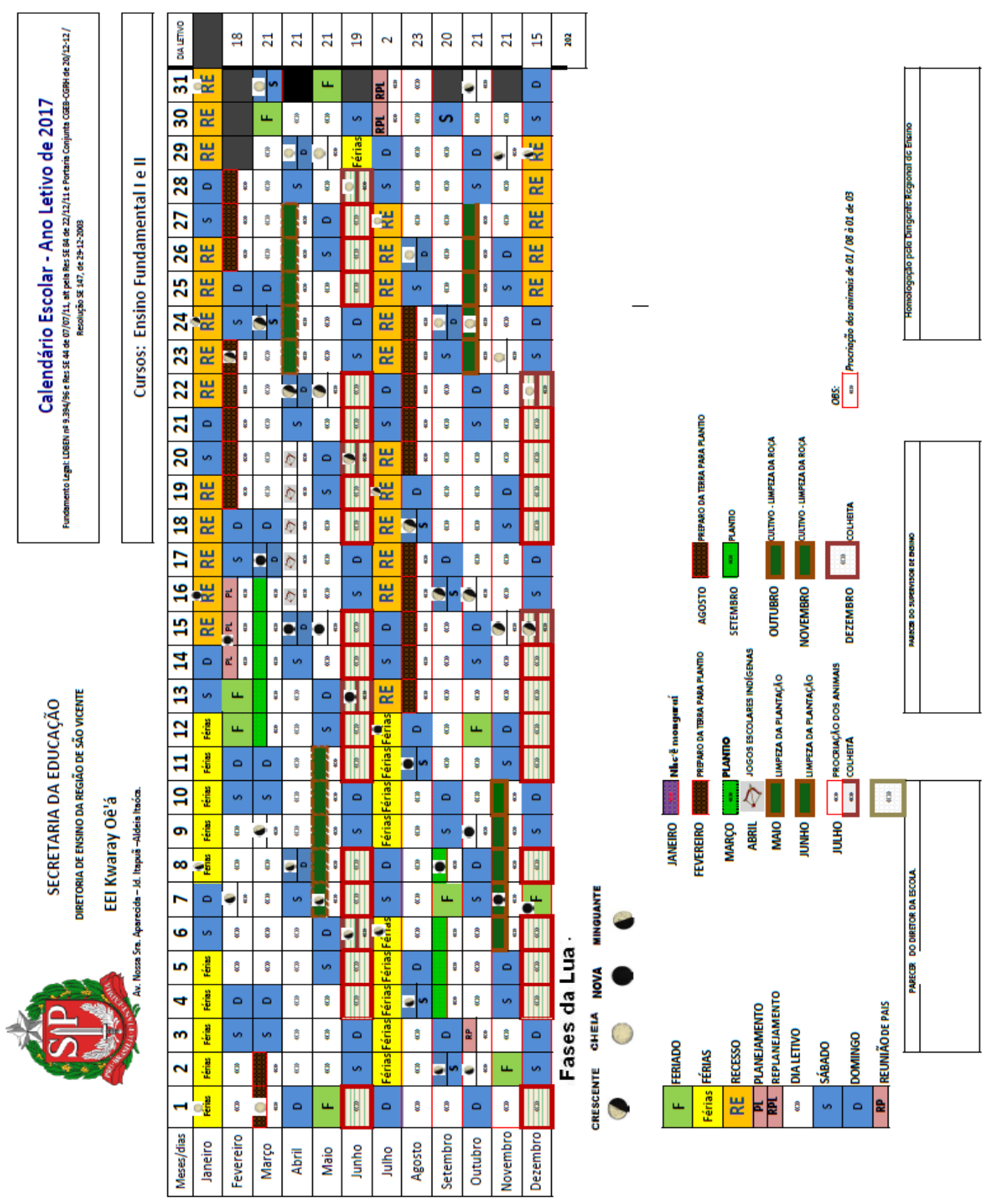

